\title{
Tarihsel Süreçte Rebus ve Kullanım Alanları
}

Ece ÇALIŞ ZEĞEREK*

\author{
Zeğerek, E. Ç. (2019). Tarihsel süreçte rebus ve kullanım alanları. \\ YEDI: Sanat, Tasarım ve Bilim Dergisi, Yaz 2019 (22), s. 31-40 \\ Derleme Makale / Review Article
}

özet

Bireyler tarih boyunca birbirleriyle iletişim kurmak için değişik yollara başvurmuşlardır. İletişim süreci kimi zaman doğrudan, kimi zaman da dolaylı olarak gerçekleşmiştir. Bu doğrultuda rebus bir iletişim aracı olarak karşımıza çıkmaktadır. Alfabenin ve dilsel iletişimin olmadığı zamanlarda insanlık duygu ve düşüncelerini mağara duvarlarına resmederken bir bakıma rebus'un en ilkel halini de keşfetmiştir. Bu durum Sümer ve Mısır uygarlıklarının kullandığı yazının en ilkel örnekleri olan piktografik yazıların icadına kadar sürmüş, sonraları rebus kullanımı Rönesans’ın başlangıcından günümüze kadar sanatsal ya da eğitim amaçlı kullanım alanlarında kendisini göstermiştir. Kimi zaman bir tabloda, kimi zaman bir mektupta, kimi zaman da grafik tasarım ürünü olan ticari bir logo tasarımında ortaya çıkmaktadır. Öte yandan teknolojinin gelişimi ve cep telefonlarının ortaya çıkmasıyla uluslararası bir iletişim dili olan 'emoji’ karakterleriyle de rebus, varlığını günlük yaşamda da sürdürmekte ve başka mecralarda da sürdürmeye devam edecek gibi görünmektedir.

Anahtar sözcükler: Rebus, Resfebe, Resimli Bulmaca, Resimli Alfabe, İletişim.

\section{The History of Rebus and Where It is Used}

\section{Abstract}

Throughout history, people have employed varied methods for communication. The process of communication has sometimes been direct while at other times it has been indirect. Within this context, rebus catches attention as a means of communication. In the distant past, when there was no alphabets or linguistic communication, man used to paint their feelings and thoughts on cave walls. Those people were, in a way, discoverers of the most primitive form of rebus. That practice continued until the invention of pictographic writing, the most primitive example of the writing system used by the Sumerian and Egyptian civilizations. Much later, rebus was in use for either artistic or educational purposes from the beginning of the Renaissance to the present day. Sometimes we see them on a painting or in a letter or sometimes in a commercial logo design created by a graphic designer. In addition, with the emergence of mobile phones and other similar technological devices, rebus continues to exist through emogies images, a universal communication means, in everyday life and it seems that it will continue to exist in new areas of life in future.

Keywords: Rebus, Resfebe, Picture Puzzle, Illustrated Alphabet, Communication. 


\section{Giriş}

Köklü bir geçmişe sahip olan, ancak ülkemizde çok fazla ele alınmamış bir konu olan 'Rebus' kelimesinin sözlük karşılığı, bir hecenin ya da sözcügüü temsili olarak sözü edilen sözcügün ya da hecenin sesine benzeyen bir başka nesnenin resmi ile gösterilmesidir (Britannica, 2018). Bir başka tanıma göre rebus, kelimelerin alışılmış şekilleri dışında resimlerin, harflerin veya sembollerin belirli kelimeleri veya cümleleri temsil ettiği bir kod ya da referanstır. Rebus kelimesi, 'kelimelerle değil, şeylerle' anlamına gelen Latince 'nōn verbīs sed rebus' cümlesindeki 'şeylerle' kelimesine karşılık gelmektedir (Whiting, 2017). Heller ve Vienne'a (2016, s. 93) göre ise rebus; "anlamlı bir kelime ya da kelime öbeği oluşturmak için görsellerle harfleri ve/veya kelime parçalarını bir formla birleştiren görsel bulmacalar olarak da tanımlanmaktadır”. Öyle ise hece, kelime veya kelime gruplarının rakam, harf ya da sembollerle/ resimlerle gösterilmesi işlemini rebus olarak tanımlayabiliriz. Yazılışı ve okunuşu farklı olan dillerde rebus kullanımı daha yaygın ve kolaydır. Örneğin İngilizce'de ‘eye’ (tr:göz) kelimesi ile 'I' (tr:ben) kelimesinin telaffuz ediliş şekli aynıdır. 'I' kelimesi yerine göz resminin kullanılması yani bir kelimenin, aynı telaffuza sahip başka bir kelime ile ya da kelimenin görseli ile gösterilmesi bir rebus kullanımına olanak sağlamaktadır.

'Resimli alfabe' ya da 'resimli bilmece' olarak dilimize geçen rebus kelimesi, Türkiye'de 'resim' ve 'alfabe' kelimelerinin hecelerinin birleşiminden oluşturulan 'resfebe' kelimesi ile adlandırılmaktadır. Konu ile ilgili bazı internet kaynaklarında ${ }^{1}$ resfebe kelimesinin Türkiye'de ilk kez Köksal Karakuş ve Cihan Altay tarafından kullanıldığı görülse de Türk Dil Kurumu Sözlügü’nde yer almayan bu kelimenin kökeni hakkında akademik bir kaynağa ulaşılamamıştır. 2002 yılından itibaren yayında olan Akıl Oyunları Dergisi'nde ve Türk Beyin Takımı Yarışmaları'nda resfebe sorularına yer verilmiş, Türkiye Zeka Vakfı yarışmalarında da Emrehan Halıcı tarafından resfebe soruları hazırlanmıştır. Bunun yanı sıra Serkan Yürekli, Kahraman Gündüz, Hasan Yurtoğlu ve Oğuz Saygın gibi isimler de resfebe yazarları arasında yer almaktadır (Yurtoğlu, 2017). Öte yandan Latince kökenli olan bu kelime, dilimize her ne kadar resfebe (resimli alfabe) olarak geçmiş olsa da kavramın tarihsel sü-

1 Bkz. https://www.bilgikilavuzu.com/cocuklar-icin-altin-degerinde-zeka-oyunu-resfebe/; https://resfebekutuphanesi.com/sy3/; http://www. matematik.us/resfebe-nedir.html; https://karesi.meb.gov.tr/meb_iys_dosyalar/2019_02/07171458_resfebe_bros807u776r.pdf reç içerisindeki değişim ve gelişim sürecine bakıldığında ve özellikle tasarım bağlamında yer alan örnekler incelendiğinde yalnızca resimli alfabe olarak tanımlamanın yetersiz kalacağı düşünülmektedir. Bu nedenle araştırma kapsamında daha evrensel bir kullanım olan ve 'şeyler' anlamına karşılık gelen 'rebus' kelimesi tercih edilmiştir.

ülkemizde daha çok eğitim-öğretim sürecinde, öğrencilerin analitik düşünme becerisini ve hayal gücünü eğlenceli bir biçimde geliştirmek amacıyla rebuslara başvurulmaktadır. Ancak Türkçe'de yapısı gereği -yazım ve telaffuzun aynı olması nedeni ile- rebus ilkesini uygulamak, okunuşu ve yazılışı farklı olan dillere göre daha zordur. Dilimizde eşyazım$l_{1}{ }^{2}$ ve eşsesli ${ }^{3}$ kelimeler ile rebus oluşturulabilmektedir. Örneğin eşyazımlı bir kelime olan ancak farklı anlamlara gelen 'yüz' kelimesi bilindiği gibi rakam anlamında, surat anlamında ve yüzmek fiili anlamında kullanılabilmektedir. Yüzmek anlamına gelen yüz kelimesi için rakam ile 100 yazılması ya da taşınabilir bir telefon ağını belirten ve yabancı dilden gelen 'Aycell' kelimesi yerine kişi ismi olan 'Aysel' kelimesinin yazılması ise (Günay, 2007, s. 203) eşsesli bir kelime örneğidir. Dilimizde en bilinen rebus örneklerinden biri ' $\mathrm{C} 1=$ =Cebir' bilmecesidir. 'C' harfi ve ' 1 ' rakamının okunuşları (ce+bir) 'Cebir' kelimesini oluşturmaktadır. K10 (Kon), 12M (Birikim) örnekleri de harf ve rakamın birlikte kullanılması ile oluşturulan rebus örnekleridir (Yurtoğlu, 2017).

Hayal gücü ve zekânın buluşma noktası olan rebuslar ile amaçlanan zihnin farklı düşünme şekillerini ortaya çıkararak yaratıcılığı, bilgi ve hafıza ile birleştirmek, aynı zamanda eğlenceli bulmacalar çözmek/oluşturmaktır (Yurtoğlu, 2017). Saygın ve Saygın’a (2017, s. 6) göre rebus; “hayal gücünü geliştiren, bilgi ve kavram gelişimini destekleyen, analitik düşünme becerisini geliştiren, stratejik düşünme kapasitesini, algılama ve muhakeme becerisini arttıran, dikkat ve konsantrasyonu destekleyen, aktif düşünme süreçlerini de hızlandıran” bir zihin oyunu olarak görülmektedir. Nitekim günümüzde bu zihin oyunu eğitim-öğretim sürecini desteklemek ve eğlenceli oyunlar oynamak amacıyla kullanılmaktadır.

Oldukça eski bir geçmişe sahip olan rebus'un ülkemizde kullanımının detaylı bir biçimde ele alınmamış olması bu çalış-

\footnotetext{
2 Eşyazımlı (fr. Homographie): Anlamları farklı, sesletimleri farklı ancak yazılışları aynı olan sözcükler için kullanılır (Günay, 2007, s. 201).

3 Eşsesli (fr. Homophonie): Anlamları ve yazılışları farklı, sesletimleri aynı olan sözcükler için kullanılır (Günay, 2007, s. 203).
} 
ortaya çıkış amacıdır. Dolayısıyla bu çalışmanın alanyazındaki bir eksikliği gidererek farklı disiplinlerdeki araştırmacılara yol göstereceği düşünülmektedir.

\section{Geçmişten Günümüze Rebus ve Kullanım Alanları}

Rebusun ilk kullanım amacının, yazının icadından önceki dönemlerde iletişimi sağlamak için olduğu düşünülmektedir. Resimli bulmaca olarak adlandırılan bu ilkel dil, tüm alfabelerin temelini oluşturmaktadır. Nitekim Yazı, İnsanlığın Belleği (Jean, 2018) adlı kitapta yazının temel taşına dönüşecek bir çocuk oyunu olan resimli bulmacalardan söz edilmekte ve bütün gerçek yazıların temelinde bu önemli buluşun yattığı vurgulanmaktadır:

Sümerler'in ya da eski Mısırlılar'ın hayranlık uyandıran incelikleri, bir çocuk oyunu kadar basit bir yöntemi, resimli bulmaca yöntemini kullanmaları olmuştur. Doğrudan doğruya nesneyi canlandıran bir resimden değil de, ses açısından ona yakın bir nesneden yararlanma düşüncesi böylece ortaya atılmıştır. Tıpkı bizim resimli bulmacalarımızda bir kedi ve bir çömlek resminin, aslangillerden bir hayvana ve bir saklama kabına değil de ses benzeşiminden dolayı şapkaya gönderme yapması gibi. (Fransızca 'chat' (kedi) ve 'pot' (çömlek) sözcüklerinin birlikte söylenişi 'chapeau’ (şapka) sözcüğünün okunuşunu verir) (Jean, 2018, s. 16).

M.Ö. 3500 yıllarında uygarlığın hızla geliştiği Sümer'de ve Mısır'da kullanıldığı bilinen resim-yazıların yani piktografların, rebusların ilk örnekleri oldukları söylenebilir. Sözü edilen piktograflar bir araya getirildiğinde çoğu zaman bir düşünceyi de ifade edebildiği için ‘ideogram' (düşünce yazısı) olarak da adlandırılmıştır (Jean, 2018, s. 14). Sümer'de çivi yazısı, Mısır'da ise hiyeroglif yazı haline gelen ve yan yana sıralanmış şekillerden oluşan resim-yazıları güneş, ay, rüzgar gibi geniş kavramları veya bir kelimeyi anlatmaktadır. Şekilleri sadeleştirilerek kolay çizilebilen resimler haline gelen bu yazıların çoğalması ve her şeklin bir kelimeye karşılık gelmesi ile resim-yazıları değişime/gelişime uğramış, zamanla 'kelime yazısı' (logografi), ‘hece yazısı' (fonografi) ve 'harf yazısı' (akrofoni) halini alarak soyut kavramların anlatımı kolaylaşmış, günümüz alfabesinin de oluşumuna önemli bir katkı sağlamıştir.

İlk yazılı göstergelere muhasebe kayıtlarını tutan kil tabletlerde rastlanan Sümer'de çoğunlukla tek heceli kelimelerden meydana gelen kelime yazısına (logografi) rastlanmaktadır. Örneğin bir öküzü ifade etmek için öküz başını gösteren basitleştirilmiş resimler birer kelime yazısıdır (Resim 1) (Jean, 2018, s. 14).

\begin{tabular}{|c|c|c|c|c|c|}
\hline $\begin{array}{l}\text { Resimsel } \\
\text { işaretler } \\
\text { M.0. } 3100\end{array}$ & Yorum & $\begin{array}{l}\text { Civi YazıIs Ișareti } \\
\text { M.O. } 2400 \text { civarı }\end{array}$ & 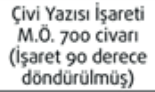 & Ses Değeri & Anlam \\
\hline & Boğa Başs & & & $\mathbf{g u} \mathbf{u}_{4}$ & Öküz \\
\hline
\end{tabular}

Resim 1. Sümerler yazısında öküz başı sembolü.

Eski Misır buluntularından olan Rosetta (Reşit) Taşı'nın 1822 yılında Jean-Francois Champollion tarafından deşifre edilmesiyle birlikte ise hiyeroglif yazıların da heceli ve ideografik bir yapıya sahip olduğu görülmektedir. Örneğin Kral Narmer tabletinde 'Narmer' ismi hece yazısı (fonografi) ile yani N'r; Nar (balık) ve Mr; Mer (yontma kalemi) anlamına gelen iki hiyeroglif sembol ile gösterilmiştir. Bu sembollerin sessel ifadesi ile de Kral Narmer'in ismi oluşturulmuştur (Voight, 2015, s. 270) (Resim 2).
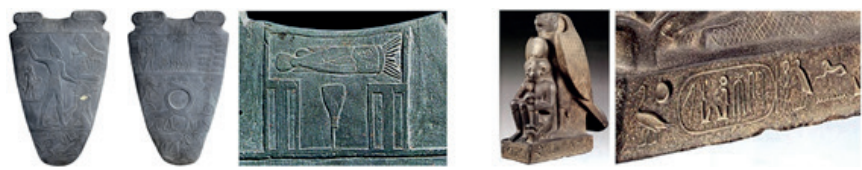

Resim 2. Kral Narmer Tableti ve Narmer isminin yazılışı, Antik Mısır, M.0̈. 3100. Ramses Heykeli ve Ramses isminin yazılışı, (1290-1224 BC) (in the Cairo Antiquity Museum).

ती Misır firavunlarından II. Ramses'in tabletlerinde olduğu gibi ünlü heykelinde de hece yazısı kullanılmıştır. Heykelde Horus'u simgeleyen bir şahin figürü altında oturan ve elinde bir bitki tutan çocuk figürü görülmektedir (Resim 2). Heykelin kaidesi üzerinde, bir kartuş (oval çerçeve) içerisinde yer alan hiyeroglif semboller ise Ramses ismine işaret etmektedir: Ramses (Ramsses/Ramessu) isminin bu heykel üzerinde 'Ra' olarak telafuz edilen güneş tanrısı Horus sembolü, 'mes' olarak telaffuz edilen çocuk sembolü đe 'su' olarak telaffuz edilen bitki sembolü $\Downarrow$ olmak üzere üç işaretten oluştuğu görülür (Imhotep, 2012, s. 17). Bu sembollerin deşifresi ile de Ra-mes-su kelimesi ortaya çıkar.

Sümer ve Mısır uygarlıklarında görülen ve aslında rebus özellikleri taşıyan bu resim-yazıların erken dönem Çin piktografları, Maya hiyeroglifleri gibi başka kültürlerde de kullanıldığı araştırmacılar tarafından vurgulanmaktadır (Voight, 2015, s. 270). Örneğin Danimarkalı dilbilimci Dienhart, Maya hiyerogliflerinin birleşik bir anlamı olduğunu ileri sürmektedir: 'Yıldırım çakması' anlamına gelen ‘lemba' kelimesinin ilk 
kısmı olan 'lem' (vessel) yük gemisi ve ikinci kısmı olan 'ba' bone (kemik) anlamına gelmektedir. Sessel benzerliğe sahip olan iki kelimenin bir araya gelmesi ile oluşan yeni kelime ise yer isimlerinde, şehir adlarında kullanılmakta veya diğer dünyaya açılan kapı olarak adlandırılmaktadır. Sözü edilen bu toplumlarda rebus, alfabetik bir iletişim aracı olarak kullanılmakta iken, zaman içerisinde gelişerek Ortaçağ Avrupası'nda imza ve armaların yanı sıra edebi metinler ile plastik sanatlarda da birer bilmece unsuru ya da şifre olarak kullanılmış, özellikle aileleri temsil eden hanedanlık isimlerinin/soyadlarının ifade edilmesi için popüler bir yöntem olmuştur. Nitekim İngiltere'nin Norvich kentinde yaşamış olan piskopos Walter Lyhart'ın (d.-ö.1472) soy isminin Ly+Hart şeklinde hecelenmesi ile 'uzanmak' ve 'geyik' kelimeleri ortaya çıkmaktadır. Nitekim Norvich Katedrali'nde taşa oyulmuş olarak görülen ve bir su birikintisi içerisinde yer alan geyik resmi, Lyhart soy ismini temsil eden bir rebus'dur. Benzer bir şekilde Exterel Katedrali'nin duvarında piskopos Hugh Oldham'ın (1519) rebusu, owl (baykuş) ve dom şeklinde hecelenerek, bir baykuşun ağzında tuttuğu kağıt üzerindeki 'dom' yazısı ile birlikte resmedilmiştir (Boutell, 1863, s. 118). Sessel benzerliklerden yararlanılarak oluşturulan ve soy ismi niteleyen William Bolton'a (1509-1532) ait bir başka rebusta ok anlamına gelen 'bolt' kelimesi ile fıçı anlamına gelen 'tun' kelimelerinin birlikte telaffuz edilmesi ile oluşan soy isim, bir fıçının içerisinden geçen ok sembolü ile gösterilmiştir (Resim 3) (Crow, 1994, s. 20-21).
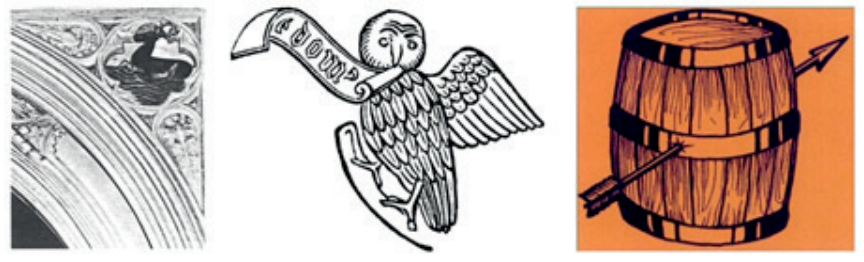

Resim 3. W. Lyhart Rebusu, Norvich Katedrali, 15. yy. Hugh Oldhoam Rebusu, Exterel Katedrali, 16. yy. William Bolton Rebusu, 16. yy.

Rebus bir eğlence, bilmece ya da şifre olmasının yanı sıra okuma-yazma bilmeyenlere, özellikle çocuklara hitap edebilmesi açısından da sıklıkla kullanılmıştır. 15. yy.'da İngiltere'de The Book of Hours kitabında Richard Shearman'ın ismi, ry-car-d şeklinde hecelere ayırılarak ve 'car' hecesi için eşsesli başka bir kelime kullanılarak gösterilmiştir (Resim 4). Soyadını temsil etmek için ise shear (makas) ve man (adam) kelimelerini karşılayan resimler kullanılmıştır. 1783 yılında yine İngiltere'de Hodson yayınevinden çıkan ve çizimlerini İngiliz illüstratör Thomas Bewick'in yaptığı, çocuklar için resimli-bulmacalardan oluşan İncil Kitabı yayınlanmıştır. 1788 yılında ise Amerikalı yazar Isaiah Thomas hiyeroglif İncil Kitabı'nı üretmiştir (Resim 4) (Olaf, 2013).
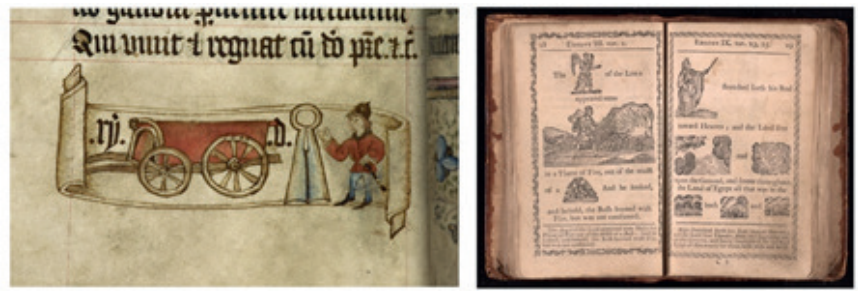

Resim 4. The Book of Hours', Richard Shearman, 15.yy. Isaiah Thomas, 1788.

İtalyan Rönesans'ı ile Fransa ve ardından da Almanya'da Geç Rönesans dönemlerinde plastik sanatlarda, resimli bilmecelerin (pictorial riddles) kullanımı oldukça popüler hale gelmiştir (Voigt, 2015, s. 269). Kimi zaman sanatçının imzası olarak kimi zaman ise resimdeki bir nesneye atıfta bulunarak rebus oluşturulduğu görülmektedir. Öyle ki İtalyan ressam Lorenzo Lotto’nun ‘Lucina Brembati Portresi’nde sol üst köşede yer alan ay (İtalyanca: Luna) resmi, içerisinde tam ortaya yazılan CI harfleri ile birleştirildiğinde 'LuCIna' sözcügü okunmaktadır (Resim 5).
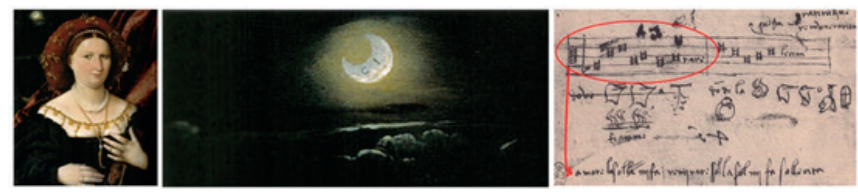

Resim 5. The Book of Hours', Richard Shearman, 15.yy. Isaiah Thomas, 1788.

İtalyan sanatçı ve bilim insanı Leonardo da Vinci de fırsat buldukça not defterlerinde resim ve harfleri bir araya getirerek kelimeler üretmiş ve cümleler yazmıştır. Leonardo da Vinci'nin rebus eskizleri, yaratıcılığına katkı sağlamak amacıyla eğlenceli zihin egzersizleri yapmış olabileceğinin bir göstergesi olabilir. Da Vinci'nin günümüze ulaşan ve Windsor Kraliyet Kütüphanesi'nde korunan eskizleri arasında yaklaşık olarak 160'tan fazla rebus çizimin olduğu (Spinelli, 1983), bu rebusların deşifresinin ise Augusto Marinoni tarafından yapıldığı bilinmektedir (Winternitz, 1982, s. 90). '0' harfi ve yanına çizdiği armut (İtalyanca: 'pera') ile 'Opera' kelimesini; alevler içerisinde bir aslan ve hemen yanında yer alan masa ile de (İtalyanca: ‘leon, arde, deschi=lionardeschi’) ‘Leonardo’ keli 
mesini oluşturmuştur. Yapmış olduğu çizimleri kelime, hece ve harflerle birleştirmenin yanı sıra müzik notaları ile de sıkça birleştirmiştir. Örneğin gam dizisindeki çizimleri ve notaları peş peşe sıralayarak İtalyanca 'aşk beni eğlendiriyor' (l'amore mi fa sollazzare) cümlesi gibi birçok resimli bulmaca oluşturmuştur (bkz. Winternitz, 1982, s. 90-93). Resim 5'te yer alan Leonardo da Vinci'nin diğer bir rebusunda nota dizisi üzerinde bir balık kancası (İtalyanca: 'amo') çizimi yer almakta, ardından 're sol la mi fa re mi' notaları gösterilmektedir. Son olarak yine nota dizisi üzerinde 'rare' kelimesi ile rebus cümle tamamlanmakta ve ortaya 'Amore sola mi fa remirare' (Love alone makes me remember: Yalnız aşk yeter hatırlamama) sözleri ortaya çıkmaktadır.

Tarihte bazı ünlü kişiler de isimlerini simgeleyen imzalarını atarken rebusu kullanmıştır. En bilinen örneklerden birisi Romalı düşünür ve yazar Marcus Tullius Cicero'nun mektuplarını üç küçük daire ile imzalamasıdır. Öyle ki Cicero kelimesi Latince'de bezelye anlamına gelmektedir. Öte yandan mektuplarını ortak selamlama sözcügüü olan 'Salutem' kelimesi ile bitirmek yerine kelimenin ambigramı olan “Metulas" kelimesine karşılık gelen çizimlerle bitirmesi Cicero'nun bilmeceye olan ilgisini ortaya koymaktadır (Voight, 2015, s. 270).

Farklı kültürlerde yaratıcı ve özgün biçimlerde karşımıza çıkan rebus kullanımı Japonya'da Edo dönemi (16031868) boyunca 'Hanjimono' olarak adlandırılmıştır. Ukiyo-e sanatçısı olan Kunisada'nın ‘Aktör bulmacaları' (Yakusha Hanjimono) olarak adlandırılan eseri rebus özellikleri taşırken, Kabuki tiyatrosunda da oyuncuların giymiş oldukları kıyafetler üzerinde rebuslu piktografik resimlerin yer aldığı bilinmektedir. Bunun yanı sıra 'Egoyomi' olarak adlandırılan takvimler de, okuma yazma bilmeyen insanlar tarafından okunabilmesi için rebus içeren resimler ile hazırlanmıştır (Voight, 2015, s. 270).

18. yüzyılda Fransa'da bir iletişim aracı olarak ve bir statü göstergesi ya da sosyal çevrenin belirleyicisi olarak kullanılan buluşma kartları resimli bulmacaların kullanıldığı bir başka önemli örnektir. 19. ve 20. yüzyılın başlarında Avrupa, İngiltere ve Doğu Amerika'ya hızla yayılarak popülerleşen ve ziyaret kartları olarak da adlandırılan buluşma kartları (escord card/calling card), birinci sınıf bir yaşamın vazgeçilmez bir simgesi olmuştur. Özellikle İngiltere’de Viktorya döneminde kullanılan bu kartlar, günümüzdeki sosyal medyanın ilkel bir biçimi olarak tanımlanabilecek bir yapıya sahiptir. Kimi za- man bir akşam yemeği sonrasında teşekkür etmek, kimi zaman geçmiş olsun demek ya da başsağlığı dilemek, kimi zaman ise tanışmak ya da sadece bir merhaba demek için kullanılan kartlar, rebus yöntemi ile mesaj bırakmanın olanaklarını sergilemektedir. Resim 6 örneğinde; 'I' ([/aı/] tr:ben) kelimesi, eşsesli bir kelime olan 'eye' ([/ar/] tr:göz) kelimesini temsil eden bir göz çizimi ile; 'see' ([/sic/] tr:görmek) kelimesi, eşsesli okunan C harfi (/sid/) ile; 'dear' ([/dDə/] tr:sevgili) kelimesi, eşsesli bir başka kelime olan 'deer' ([/dDə/] tr:geyik) kelimesini temsil eden geyik çizimi ile; 'home' (tr:ev) kelimesi için ise bir ev resmi kullanılmıştır. Kartta ortaya çıkan mesaj ise 'May I see you home, my dear?' (Seni evde görebilir miyim, sevgilim?) cümlesidir. Burada rebus ile verilmek istenen mesaj karmaşık bir biçimde temsil ediliyor gibi görünse de aslında kendi içinde bir bütünlük vardır ve her bir kelime/harf/resim bu bütüne hizmet etmektedir (Brantley, 2015, s. 289).

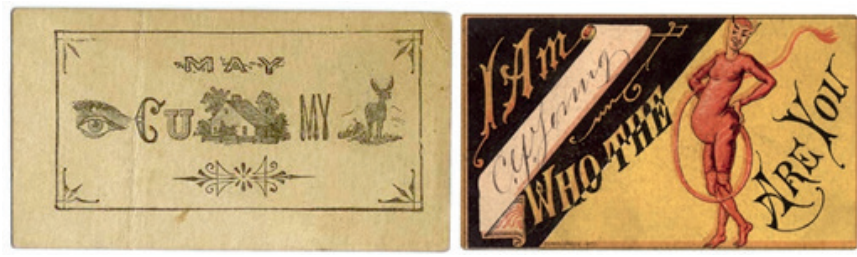

Resim 6. Buluşma Kartları, 'May I S|ee You Home My Dear?', 1860-1970. I am . Who The Devil Are You?, 1877.

Tom Sawyer'ın Maceraları hikayesinin yazarı Mark Twain ve Alice Harikalar Diyarı'nda hikayesinin yazarı Lewis Carroll dahil olmak üzere birçok ünlü yazarın rebusları mevcuttur. Twain'in 1881 yılında Montreal'den, karısı Livy’ye rebuslar içeren bir mektup yazmıştır (Resim 7). Mektupta kimi yerlerde kelime ya da hecelerin yerine resim-yazıları kullanmış olması, okumayazma bilmeyen çocuklarına da hitap etmesi içindir. Rebus mektupta yazılanlar şu cümlelere karşılık gelmektedir:

Livy dear, a mouse kept me awake last night till 3 or 4 o'clock-so I am lying abed this morning. I would not [a log with a "knot"] give sixpence [the nibs of six pens] to be out yonder in the storm, although it is only snow.

There -that's for the children- was not sure that they could read writing, especially Jean, who is strangely ignorant in some things. 


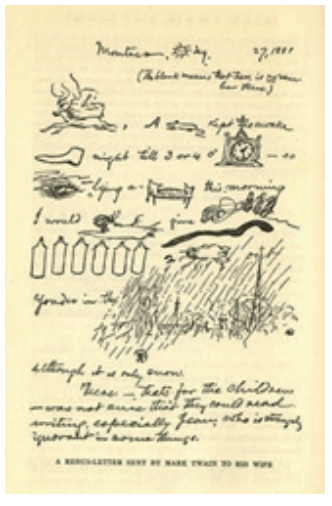

Resim 7. Mark Twain, Rebus Mektup.

Bu görsel bilmecelerin kent isimlerini simgelemek için de kullanıldığı, özellikle 20. yüzyıla doğru gelindiğinde Avrupa'da örneklerinin çoğaldığı bilinmektedir. Almanya'da bir kent olan ve Wolf (Kurt) ile Burg (Kale) kelimelerinin birleşiminden oluşan Wolfsburg'un armasına bakıldığında kale ve kurt çizimlerinden oluşturulduğu görülmektedir. Benzer bir şekilde Fransa'da bir kent olan Châteaurenard'ın, Château (Kale) ve Renard (Kurt) kelimelerinden oluşan kent armasında da kale ile kurt resimleri kullanılmıştır (Resim 8).
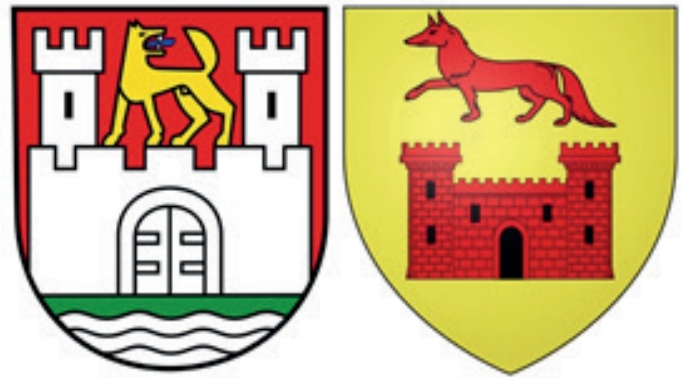

Resim 8. Wolfsburg (Wolf's Castle) Kent Arması, (Wolf: Kurt,

Burg: Kale). Châteaurenard Kent Arması, (Château = kale; Renard $=$ kurt).

Günümüze doğru gelindiğinde, ticari firmaların bazı tasarımlarında rebus ilkesi ile hareket ettikleri görülmektedir. En bilinen rebus tasarım örnekleri arasında Amerikalı grafik tasarımcılardan Milton Glaser'in New York Eyaleti Ticaret Bakanlığı için yapmış olduğu 'I ૫ NY' (I Love New York) tasarımı ile Paul Rand'ın 1981 yılında IBM şirket çalışanları için yapılan bir etkinliği tanıtmak amacıyla harf ve sembollerden yararlanarak tasarlamış olduğu afiş tasarımı (Resim 9) yer almaktadır (Heller, Vienne, 2016, s. 93). Sözü edilen bu afiş tasarım ve slogan örneğinin yanı sıra başta logo tasarımları olmak üzere reklam kampanyaları için üretilen birçok grafik tasarım ürününde de rebus ilkesinin kullanımına rastlanmaktadır. Bilinen en güncel örnek ise dijital çağın modern hiyeroglifleri olarak da adlandırabileceğimiz 'emoji’lerdir (Resim 9).

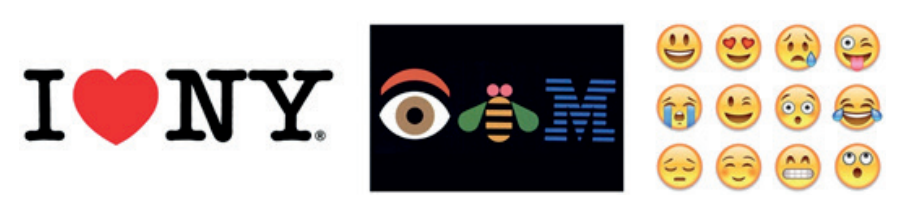

Resim 9. New York için slogan, Milton Glaser, USA, 1975. IBM Afiş Tasarımı, Paul Rand, USA, 1981. Emoji tasarımları, 2000'li yıllar.

\section{Türkiye'de Rebus Kullanımı}

ülkemizde rebus ilkesi ile oluşturulan üretimlere bakıldığında konu hakkında referans olarak nitelendirilebilecek bir kaynak bulunmadığı için ne zaman yapılmaya başlandığı ile ilgili bir bilgiye ulaşılamamıştır. Ancak Latin harflerine geçilen 1928 yılına kadar olan Cumhuriyet'in ilk yıllarında yayımlanan Resimli Dünya Dergisi'nde Osmanlıca harflerin yer aldığı rebus örneklerine rastlanmıştır. Nitekim 1924 yılından itibaren Orhan Seyfi Orhon ile yayın hayatına başlayan fenni, edebi, terbiyevi ve mizahi nitelikli haftalık bir çocuk dergisi olan Resimli Dünya Dergisi'nde çocukların eğlenceli zaman geçirmeleri ve zihinsel gelişimleri için çeşitli bulmacalara yer verilmiştir. Bu bulmacalar arasında rebus ilkesi oluşturulan bulmacalar da yer almaktadır (Resim 10). Öte yandan derginin bu bilmecelerin çözümleri için müsabakalar yaptığı da bilinmektedir (Sarıkaya, 2018, s. 18; Yıldırım, 2013, s. 39).
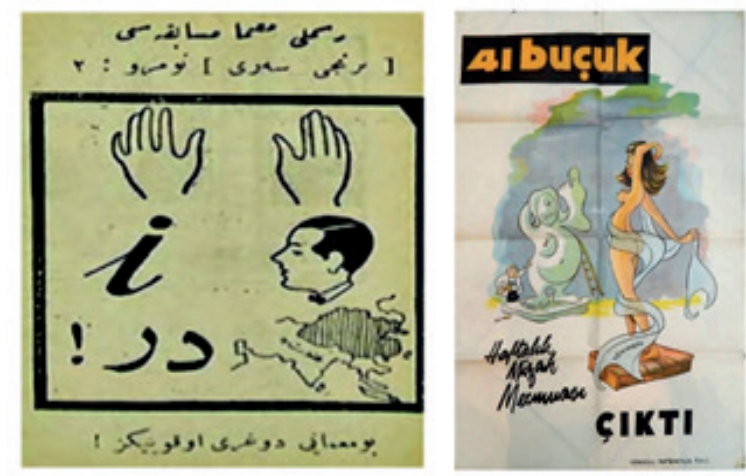

Resim 10. 'Resimli Muamma Sorusu', Resimli Dünya Dergisi. 41 buçuk Mizah Dergisi, 1952, No: 1.

Sözü edilen dergide 'resimli muamma' sorusu olarak yer alan bir rebus bulmaca ile ilgili olarak Sarıkaya aşağıdaki açıklamaya yer vermektedir: 
'Resimli Muamma' sorusu ise günümüzde Resfebe (rakam, harf ve resimle karışık verilen sözcük, deyim veya atasözü bilmecesi) olarak adlandırılan oyunun aynısıdır. Sözel yetenekleri yani hayal gücünü ve görsel zekâyı, edebi bilgisiyle ilişkilendirme algısı arttırılmak istenen çocuğa, bu oyunla keşfetme duygusunun yanında dil ve ifade gelişimi fırsatı da verilmektedir. Soruda sözel yetenek, hayal gücü ve akıl yürütme becerisini kullanan çocuğa resimdeki ipuçlarını bulma ve bunları edebi bilgi şekline getirme kabiliyeti kazandırılmaktadır (Sarıkaya, 2018, s. 19).

1922 yılında yayın hayatına başlayarak, haftada iki kez çıkan siyasi ve sosyal içerikli olan mizahi Aydede Dergisi'nde de (Kocabaşoğlu, 2012) rebus ilkesi ile oluşturulmuş bulmacaların yer aldı̆̆ı görülmektedir. Aydede Dergisi’nin 1948 yılındaki sayılarında yayınlanan ve 'fikir oyalama için bir bulmaca' ismi verilen bulmacaların birer rebus örneği olması dikkat çekicidir. Resim 11'de yer alan 91-11 numaralı örneğin deşifresi yapıldığında 'Minel bab ilel mihrab’ı okuyunuz’ cümlesinin yazdığı tespit edilmiştir. Sözü edilen cümlede yer alan Minel Bab İlel Mihrab (Kapıdan Mihraba), derginin yaratıcısı olan Refik Halit Karay’ın bir kitabının ismidir. 91-9 numaralı örnekte ise ‘Ata arpa yiğide pilav’ atasözü karşımıza çıkmaktadır (Resim 11).

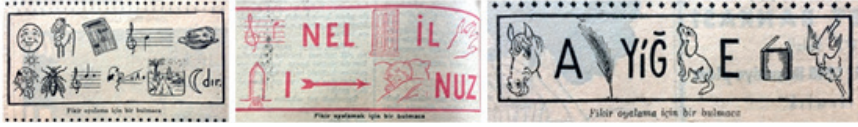

Resim 11. Aydede Dergisi, 02.06.1948, No:91-8 / 12.06.1948, No: 91-11 / 05.06.1948, No: 91-9.

Resimli Dünya ve Aydede Dergileri'nde yer alan bu bulmacalar, çocukların yaratıcı düşünebilmesini, fikir yürütebilmesini, parça-bütün ilişkisini kurabilmesini desteklemektedir. Bu yönü ile sözü edilen bulmacalar, rebusun harf inkılabı öncesinde ve sonrasında eğitim amacıyla ülkemizde kullanıldığının birer göstergesidir. Cumhuriyetin ilk yıllarında belki de daha öncesinde yayımlanan mizah ya da çocuk dergilerinde rebus kullanımına ne sıklıkla yer verildiği tam olarak bilinememektedir.

Eğitici işlevinin yanı sıra estetik kaygılar ile üretilen grafik tasarım ürünlerinde konuya uygun örnekler karşımıza çıkmaktadır ki 41buçuk Mizah Dergisi’nde rebusun resimli bul- maca olarak eğitim amacıyla değil kapakta yer alan dergi logosunda kullanıldığı görülmektedir. İlhan Selçuk-Turhan Selçuk tarafından yaratılan ve 1952 yılında yayın hayatına başlayan dergide, ismin 41,5 ya da kırk bir buçuk biçiminde yazılması yerine bir kısmı rakam, bir kısmı ise kelime kullanılarak yazılmıştır (Resim 10). Her iki yazım biçiminin sessel ifadesi ayn olduğundan dergi isminin rebus özelliği taşıdığı söylenebilir.

20. yüzyılın en büyük grafik tasarımcılarından biri olan Ivan Chermayeff tarafından tasarlanan Koç Holding logo tasarımı, rebus ilkesine uygunluk açısından oldukça iyi bir örnektir. Dünyaca bilinen birçok logo tasarımı ve kurumsal kimlik tasarımına imzasını atan, tasarımlarında sadeliği ön plana çıkaran Ivan Chermayeff'in 1984 yılında tasarlamış olduğu Koç Holding logosunda (logobook, 2019) yer alan 'koç başı' sembolü rebus logo olarak adlandırılabilir (Resim 12). Nitekim kelimenin yerine kelimeyi doğrudan niteleyen bir sembolün bir başka deyişle 'kelime yazısı'nın (logografi) kullanılması gibi, tasarımda şirket isminin yani 'koç' kelimesinin biçimsel karşılığının kullanılması, logo tasarımının hiyeroglif resim-yazılarına benzer bir bakış açısı ile üretildiğinin göstergesidir. Koç Holding'in yanı sıra Pelikan Yayınları, Mavi Kirpi Yayınları, 4gen Ağ ve Güvenlik Yazılımları, F2R (Fikir) isimli youtube kanalı, G3 Mimarlık, 5Yıldız gibi daha birçok uluslararası, ulusal ya da yerel markalar da tasarımda bir anlatım biçimi olarak bu ilkeyi kullanmayı tercih etmiştir.

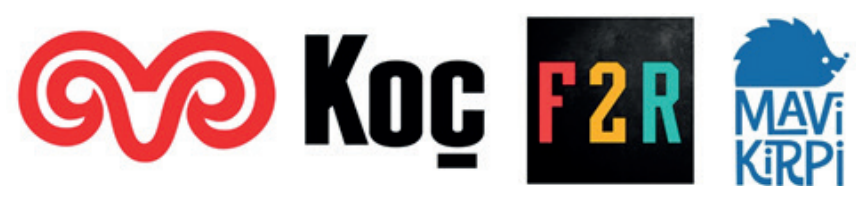

Resim 12. Rebus Logo Örnekleri; Koç Holding, Fikir Youtube Kanalı, Mavi Kirpi Yayınları.

Hem dünyada hem de ülkemizde farklı disiplinlerde, farklı amaçlarla kullanımı olan rebus ilkesi ile ilgili ulusal kaynaklara bakıldığında Oğuz Saygın ve Ekrem Saygın'ın Resfebe Resimli Kelime Oyunlarr (2017), Elvin Öven'in İnci'nin Resfebe Merakı (2018) gibi çocuklar için eğlenceli zeka oyunları içeren kitaplar bulunmaktadır. Akademik yayınlara bakıldığında ise konuyu doğrudan ele alan herhangi bir kapsamlı bir kaynağa rastlanmamıştır. Ancak 'Özel Yetenekli Öğrencilerin Coğrafya Derslerinde Bir Farklılaştırma Örneği Olarak Resfebenin Kullanımı' başlıklı makalede (Yurteri ve Mertol, 2018) bir öğretim metodu olarak; 'Türkiye Cumhuriyeti’nin İlk Yıllarında Yayınlanan Çocuk Dergilerindeki Akıl Oyunları Örnekleri’ başlıklı 
makalede (Sarıkaya, 2018) çocuklar için yayınlanan bulmaca örneği olarak; 'Afişte İllüstrasyonun Anlatım Biçimleri' başlıklı makalede (Gedik ve Taşçıŏlu, 2018) ise 'Anlam Oyunları ve Nükte ile Anlatım' başlığı altında afiş tasarımında bir anlatım biçimi olarak kısaca söz edildiği görülmüştür.

\section{Sonuç}

Yüzyıllardır göstergeler ve tasvirler aracılığı ile iletişim kurmanın birçok yöntemi bulunmuş ve kullanılmıştır. Bu yöntemlerden biri olan rebusun Mezopotamya'da başlayan serüveni, diğer toplumlarda da zamanla gelişerek değişime uğramıştır. Hesap kaydı tutmak gibi çok basit bir nedenden doğarak rebus ilkesi doğrultusunda oluşan yazı, zamanla farklı medeniyetler tarafından piktogramlar, ideogramlar, fonogramlar gibi değişik şekillerde yorumlanarak günümüze kadar gelmiştir. Dolayısıyla yazının temel taşını oluşturan ve sesi temel alan birer gösterge olan resimli bulmacalar yani rebuslara farklı amaçlarla başvurulsa da, ilk kullanım amacının iletişim kurmak olduğu açıktır. Okuma-yazma oranının düşük olduğu dönemlerde yine iletişim kurma amacı taşıyan, sonraları özellikle çocuklara hitap eden rebusların üretilmesi ile iletişim kurması ile birlikte eğitici ve eğlendirici bir işlevinin de olduğunu göstermektedir. Öte yandan birçok yazar, sanatçı gibi dönemlerinin önemli şahsiyetleri tarafından kullanılması ise rebusun sözü edilen işlevlerine ek olarak, kimi zaman şifre oluşturmak, kimi zaman zihin egzersizleri yapmak, kimi zaman da estetik kaygılar nedeniyle üretildiğini göstermektedir. İçinde bulunduğumuz görsel iletişim çağında tıpkı Picasso'nun resimleri ile mağara duvar resimlerine bir dönüşün görüldüğü gibi, ilk yazının ortaya çıkış ilkesi olan rebusların da cep telefonlarının mesaj uygulamalarında ideogram içeren emojiler olarak kendisini güncelleyerek karşımıza çıkması, bu ilkel iletişim dilinin hiç ölmeyeceğini ve her dönemde farklı şekillerde yine karşımıza çıkacağını düşündürmektedir. Günümüzde birçok gelişmiş yazılı/sözlü iletişim dili olmasına rağmen neden rebusların hala bir başvuru kaynağı olarak kullanıldığı sorusu gündeme gelmektedir. Bu durum görsel iletişim bağlamında düşünüldüğünde, rebus ilkesi ile oluşturulan emoji karakterleri gibi üretimleri, kimi zaman yazıdan kimi zaman ise sözden daha etkili ve/veya dili destekleyen bir iletişim aracı olarak görülebilir.

\section{Kaynakça}

Boutell, C. (1863). Heraldry, Historical and Popular, Second Edition, London: Winsor and Newton,

https://books. google.com.tr/books?redir_ esc $=y \& h l=t r \& i d=V c E Y A A A A M A A J \& q=$ oldham $\# v=s n i$ ppet $\& q=$ oldham $\& f=$ false $(25.12 .2018)$.

Brantley, J. (2015). “In Things:The Rebus in Premodern Devotion", Journal of Medieval and Early Modern Studies, 45:2, USA: Duke University Press, DOI 10.1215/ 10829636-2880899, 287-322.

Britannica, (2018). Encycloapedia Britannica, “Rebus - Wri ting Principle”, https://www.britannica.com/topic/ rebus-writing-principle (23.11.2018).

Crow, M. (1994). “The Rebus”, Anchester Magazine, Vol: 12, Number:1, 19-21 https://books.google.com.tr/books ?id=CA6MxrsK81gC\&pg=PT19\&lpg=PT19\&dq=reb us +of+Bishop+Walter+Lyhart\&source $=$ bl\&ots $=0$ WQ $7 \mathrm{E} 18 \times 00 \&$ sig $=q U \mathrm{mHnEAoXDkEnd06Q0rVI}$ hh9nu0\&hl=tr\&sa=X\&ved=2ahUKEwiq_9HPnZbfAhU ohaYKHYwpCH0Q6AEwCXoECAcQAQ\#v=onepage\&q =william\&f=false (19.12.2018).

Gedik, M. B. ve Taşçıŏlu M. (2018). “Afişte İllüstrasyonun Anlatım Biçimleri”, Anadolu Üniversitesi Güzel Sanat lar Enstitüsü Sanat ve Tasarım Dergisi, http://dergi park.gov.tr/ download/article-file/621124 (10.02.2019).

Günay, V. D. (2007). Sözcükbilime Giriş, İstanbul: Multilingual Yayınları.

Heller S. ve Vienne V. (2016). "Fikir No 43: Bilmeceler ve Görsel Bulmacalar”, Grafik Tasarrmı Değiştiren 100 Fikir, (Çev. Bengisu Bayrak), ISBN: 9789750407024, İstanbul: Literatür Ya yınları.

Imhotep, A. (2012). "Egypt in Its African Context Note 3: Towards A Method For Vocalizing Mdw Ntr Symbols", The MOCHA-Versity Institute of Philosophy and Research, http://www.asarimhotep.com/docu mentdownloads/ egyptInItsAfricanCon textNote3.pdf (20.11.2018).

Jean, G. (2018). Yazı İnsanlığın Belleği, 9. Baskı, İstanbul: Yapı Kredi Yayınları.

Kocabaşoğlu, U. (2012). “Aydede’den”, Taha To ros Arşivi, Dosya No: 87-Refik Halit Karay, http://earsiv.sehir.edu.tr:8080/ xmlui/bitstream/handle/11498/27024/00151475 
6006.pd f?sequence $=1$

Logobook, (2019). Koç Holding, http://www.logobook.com/ logo/koc-holding/ (12.02.2019).

Munis, E. (1966). Evrimi ile Yazı Sanatı, Ankara: Sevinç Mat baası.

Olaf, A. (2013). History of Rebus Puzzles, http://voolpuzz les.blogspot.com/2013/03/ history-of-rebus-puzzles. html, (30.11.2018).

Öven, E. (2018), İnci’nin Resfebe Merakı, 1. Baskı, İstanbul: Kırmızı Kedi Yayınevi.

Sarıkaya, M. (2018). “Türkiye Cumhuriyeti’nin İlk Yıllarında Yayınlanan Çocuk Dergilerindeki “Akıl Oyunları Örnekleri”, Munzur Üniversitesi Sosyal Bilimler Dergisi, http://dergipark.gov.tr/download/article-fi le/615891, (10 Şubat 2019).

Saygın 0. ve Saygın. E. (2017). Resfebe Resimli Kelime Oyunla rı, 2. Baskı, Ankara: Hayat Yayıncılık.

Spinelli, A. (1983). "I rebus di Leonardo per divertire Lu dovico il Morro”, II Corriere Sella Sera, 16.01.1983, http://www.franuvolo.it/sito/rassegnastampa/ras segna-leonardo (23.12.2018).

Voigt, V. (2015) "Rebus - Charms - Evil Forces - Magic”, Folklore Tanszék, Eötvös Loránd University, Budapest, Hungary, 269-274, http://www. folklore.ee/ liisa/ too/RY2015/articles/RY2015_26_ Voigt.pdf (29.11.2018).

Whiting, J. (2017). “Encountering Rebuses a Path of Dis covery From One Little Children's Book”, Natio nal Library of Australia, https://www.nla.gov.au/ blogs/behind-the-scenes/2017/02/06/encounteringrebuses, (23.11.2018).

Winternitz, E. (1982). Leonardo da Vinci as a Musician, Yale Univertisy Press, New haven and London, https:// www.academia.edu/27695054/Leonardo_da_Vin ci_as_a_ musician (23.12.2018).

Yıldırım, İ. O. (2013). Eski Harfli Çocuk Dergilerinden Resimli Dünya Dergisi, Kilis 7 Aralık Üniversitesi, Sosyal Bilimler Enstitüsü, Türkçe Eğitimi Anabilim Dalı, (Yayınlanmamış Yüksek Lisans Tezi), Kilis.

Yurteri ve Mertol, (2018). “Özel Yetenekli Öğrencilerin
Coğrafya Derslerinde Bir Farklılaştırma Örneği Olarak Resfebenin Kullanımı”, Kırşehir Ahi Evran Üniversitesi Sağlık Bilimleri Dergisi, Cilt 1, Sayı 2, https://sbdergi.ahievran.edu.tr/makaleler/4t7 uzz tammetin. pdf (20.01.2018).

Yurtoğlu, H. (2017). “Resfebe ve Zeka Oyunu”, ODTü Dönem Arası Seminerleri Sunumu, Ankara, 16.02.2017.

\section{Resim Kaynakları}

Resim 1. Sümerler yazısında öküz başı sembolü. https://kaynaklarlatarih.blogspot.com/2018/03/sumeryazsnn-kokeni-gelisimi-analizi.html.

Resim 2. Kral Narmer Tableti ve Narmer isminin yazılışı, Antik Misır, M.Ö. 3100. Ramses Heykeli ve Ramses ismi nin yazılışı, (1290-1224 BC) (in the Cairo Antiqu ity Museum).https://apuntesdeartedebachillerato. blogspot.com/2017/11/arte-egipcio-diapositivas. htmlhttps://c1.staticflickrcom/8/7258/7731902190_ cf41a025ea_b.jpg.http://dangxia.org/englishfile/ori gin.html

Resim 3. W. Lyhart Rebusu, Norvich Katedrali, 15. yy. Hugh Oldhoam Rebusu, Exterel Katedrali, 16. yy. William Bolton Rebusu, 16. yy. https://i.pinimg.com/originals/9c/73/6d/9c736d381 b7de5cbe7ac1e6aff62fcbd.jpg. https://books.google.com.tr/books?redir_esc=y\&hl=t r\&id=VcEYAAAAMAAJ\&q=lyhart\#v=snippet $\& q=$ lyhart $\& f=$ false.https://books.google.com.tr/books?id=CA6 MxrsK81gC\&pg=PT19\&lpg=PT19\&dq=rebus + of + Bish op + Walter + Lyhart\&source $=$ bl\&ots $=0$ WQ7E18x00\&si $\mathrm{g}=\mathrm{qU} \mathrm{mHnEAoXDkEnd0600rVlhh9nU0 \& hl=tr \& sa=X \&}$ ved=2ahUKEwiq_9HPnZbfAhUohaYKHYwpCH0Q6AEw $C X o E C A c Q A Q \# v=$ onepage $\& q=$ william\& $f=$ false.

Resim 4. 'The Book of Hours', Richard Shearman, 15.yy. Isaiah Thomas, 1788.

http://www.bl.uk/catalogues/illuminatedmanusc ripts/ILLUMIN.ASP?Size $=$ mid $\& I l I D=58315$. https://www.loc.gov/exhibits/stjohnsbible/images/ sjb0040b.jpg.

Resim 5. Lorenzo Lotto, Lucina Brembati Portresi, 1523. Leonardo da Vinci Rebus Yazı: 'Amore sola mi fa re mirare'. 
http://shows.we-envision.com/aa/2big/LOTT0,\%20 Lorenzo/b76911.JPG.

https://www.tuttartpitturasculturapoesiamusica. com/2015/09/Leonardo-da-Vinci-Trattato-dellaPittura.27.html\#more.

Resim 6. Buluşma Kartları, 'May I See You Home My Dear?', 1860-1970.

I am . Who The Devil Are You?, 1877.

https://cdnnatgeo.nikkeibp.co.jp/ news/16/010600002/ph_thumb.jpg?_. scale=w:500,h: 231\&_sh=0a90860f00; https://blog.victoriantradingco.com/2016/02/01/ flirtation-cards/.https://static1.squarespace.com/ static/5672361ad8af10a9410683b3/t/589c50ede3 df285dc9169901/1486639347837.

Resim 7. Mark Twain, Rebus Mektup.

http://bancroft.berkeley.edu/Exhibits/mtatplay/lite rarymischief/rebusletter.html.

Resim 8. Wolfsburg (Wolf's Castle) Kent Arması, (Wolf: Kurt, Burg: Kale). Châteaurenard Kent Arması, (Château= kale; Renard = kurt). http://media05. myheimat. de/2013/09/15/2826520_web.jpg. https://simple.m.wikipedia.org/wiki/Châteaurenard.

Resim 9. New York için slogan, Milton Glaser, USA, 1975.

IBM Afiş Tasarımı, Paul Rand, USA, 1981. Emoji tasa rımları, 2000'li yıllar.

http://npnconference.org/wpcontent/uplo ads/2016/01/ILNYlogo_horizontal.jpg. https://pbs.twimg.com/media/DZpvURzU8AAUPv2. jpg:large.

http://www.startribune.com/why-use-words-emojisconvey-health-just-fine-mayo-finds/464063023/.

Resim 10. 'Resimli Muamma Sorusu', Resimli Dünya Dergisi.

41 buçuk Mizah Dergisi, 1952, No: 1.

http://dergipark.gov.tr/download/article-fi

le/615891.

https://c1.staticflickr.com/9/8367/8558724460_7e7 b58bb87_b.jpg.

Resim 11. Aydede Dergisi, 02.06.1948, No:91-8/

12.06.1948, No: 91-11 / 05.06.1948, No: 91-9. İs tanbul Mizah Müzesi, Aydede Dergisi, Yıl: 1948-49, Cilt 1-2 FS.
Resim 12. Rebus Logo Örnekleri; Koç Holding, Fikir Youtube Kanalı, Mavi Kirpi Yayınları. https://www.koc.com.tr/tr-tr/ koc-gundem/koc-toplulugu-marka-iletisim/ logolar?Term StoreId=8c9329d1-69ab-4175b88c-024843c73990\&TermSetId $=75$ bd7bc9-856e4298-9c9b-9bdfa053e58d\&TermId=fed7525e-0a9247b8-ac1b-eb86c19967c7. https://www.youtube.com/channel/uCa p13u40cw1qrScNy9AMjWA; http://mavikirpi.com.tr/ wp-content/uploads/2017/09/mavi_kirpi.jpg. 